\title{
Diagnostic value of fingerprint patterns: An explorative study on beta-thalassemia diagnosis
}

\author{
Hassan Solhi ${ }^{1}$, Mojgan Hashemieh ${ }^{2}$, Mohammad Lorgard Dezfuli Nejad ${ }^{3}$, Hamid-Reza Khoddami \\ Vishteh $^{3}$ and Maryam Rahmati Nejad ${ }^{4}$ \\ ${ }^{1}$ Department of Forensic Medicine \& Toxicology, School of Medicine, Arak University of Medical \\ Sciences, Arak; ${ }^{2}$ Department of Hematology \& Oncology, Shahid Beheshti University of Medical \\ Sciences, Tehran; ${ }^{3}$ Universal Network for Health Information Dissemination and Exchange (UNHIDE), \\ Tehran; ${ }^{4}$ School of Medicine, Arak University of Medical Sciences, Arak, Iran.
}

\begin{abstract}
Rapid diagnosis of major $\beta$ thalassemia along with certain preventive measures is of utmost significance. The present study aims to compare the fingerprints in Major $\beta$ thalassemic patients (67) and in their parents (76 with minor thalassemia) with the normal fingerprints of control group (144). A forensic medical examiner determined fingerprint types of arch, loop, whorl and other types. Like normal individuals, loop fingerprint pattern was found to be the most common fingerprint type among thalassemic patients. However, the number of whorl fingerprints in all fingers in thalassemic patients was greater than that of normal individuals and the number of loop fingerprints was smaller $(\mathrm{p}<0.05)$. Arch type fingerprint pattern was less frequent in major thalassemic patients compared to minor thalassemic ones $(p<0.05)$. The findings show that the number of whorl fingerprint patterns in thalassemic patients was greater than that of normal individuals, while the number of loop fingerprint patterns being smaller and the frequency of arch fingerprint pattern in patients with major thalassemia was lower than that of minor thalassemic patients. Therefore, one may choose fingerprint pattern as a simple, affordable and appropriate screening method to help detect the afflicted patients and prevent severe cases of thalassemia.
\end{abstract}

\section{Introduction}

Thalassemia is the world's most common hereditary hemoglobinopathy ${ }^{1}$, and depending on which globin production chain has been disrupted, it may be classified into alpha, beta, delta and other types. The hereditory prevalence rate of this disease varies between $2.5 \%$ and $15 \%$ in the Mediterranian regions, the Arabian Penninsula, Turkey, Iran, India and Southeastern Asia $^{2} . \beta$ Thalassemia is the most common type of thalassemia manifested in three forms of minor thalassemia, intermediate thalassemia, and major thalassemia. With an estimated number of 25000 major thalassemic patients and three million minor thalassemic individuals, Iran counts as one country with abnormally high rate of $\beta$ thalassemia so much so that to be reported as the most common hereditory disease in the country ${ }^{3}$. The prevalence rate of this disease is $10 \%$ in the coastal regions of the Caspian Sea and the Persian Gulf and varies between $4 \%$ and $8 \%$ in the rest of Iran $^{2}$.

Since major $\beta$ thalassemia is concurrent with severe anemia and hemosydrosis and affected patients need repeated blood transfusion, this disease is counted not only as a health problem but also because of the severe harms and relevant care costs inccurred by the patient it counts as a socio-economic problem in countries indicating a high rate of $\beta$ thalassemia ${ }^{4}$. On the other hand, typical thalassemia diognosis methods using red blood cell indices ${ }^{5-7}$ belatedly reveal the disease because of changes in hemoglobin during fetal and postnatal periods ${ }^{8,9}$.

Therefore, health system managers today prefer to employ preventive measures through different strategies, including pre-marriage screening of couples, genetic counselling, and informing at risk couples. However, these mothods are all costly and time-consuming and may not be accessible to everyone ${ }^{10}$. 
Dermatoglyphs or fingerprints are formed between the seventh and twenty-first week of the fetus' life and is individualy unique and immutabel during life ${ }^{11}$. Determining fingerprint patterns is a non-invasive procedure which is even possibel from birth. Findings from studies show there to be a relationship between certain diseases, including Down's syndrome, mental retardation and multiple sclerosis, and certain fingerprint patterns ${ }^{12-22}$. Following suit, researchers are conducting further studies to find any possible relationship between type of fingerprints and other diseases. However, few studies have been conducted for describing dermatoglyphs disorders in $\beta$ thalassemic patients and those few ones done date back to long past having produced mixed results ${ }^{22-28}$.

Since detection of this disease in endemic countires like Iran is of high significance, employing this non-invasive detection method may contribute to rapid and cost-efficient diagnosis of this disease. Being the first of its kind in Iran, the present study attempts to compare the fingerprint patterns of $\beta$ thalassemic patients and their parents (with minor thalassemia) with those of the control group.

\section{Materials and Method}

This case-control study was conducted in 2007 at Amir Kabir Hospital (Arak, Iran). The experimntal group consisted of 67 major $\beta$ thalassemic patients together with 76 parents with minor $\beta$ thalassemia (Table I). The control group included 144 non-affected individuals with normal Mean Cell Volume (MCV) and Mean Cell Hemoglobin $(\mathrm{MCH})$ in their Cell Blood Counts (CBC). Participants in the control group were selected randomly. Entry requirements into the experiment included intact fingertips, non-existencce of fingerprintdamaging dermic diseases, burns and amputated fingers. The study had earned an approval from the ethical committee of Arak University of Medical Science and written consents were secured form all participants.

Fingerprints of all fingers on both hands were taken in ink by a trained assistant. To do so, fingertips were first cleaned of any dirt, grime or any other masking film. Afterward, the fingers were all rolled rightward from their topmost joint on the ink pad and likewise on the fingerprint paper. Fingerprint entry papers bore holders' details, including their full names, age, and sex. Finally, a forensic medical examiner who had no prior knowledge of group membership of the participants classified the types of fingerprint patterns using advanced Henry method. (a)

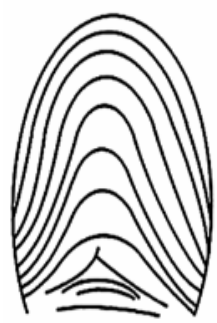

(b)

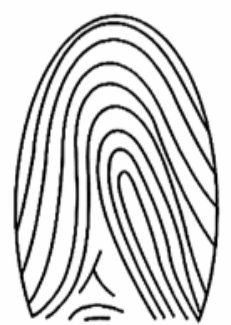

(c)

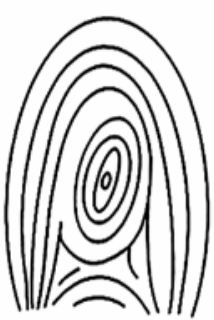

Figure 1: Major types of fingerprint patterns a) arch, b) loop, and c) whorl patterns

Only the major types of fingerprint patterns were identified, including arch, loop, whorl and other patterns (Figure 1). The latter type included three subtypes of twin loop, random loop, and lateral pocket loop which were subsumed under other type because of their low frequencies. Furthermore, those fingerprints which could not be identified due to technical limitations were also included in this category as unknown types.

Data analysis was conducted using SPSS version 13 . The total number of fingerprint types and the occurance of each type in groups were described using frequency and percentage measures. A chi sqaure test (with $\mathrm{p}<0.05$ ) was performed to examine any significant difference between the fingerprints of experimental and control groups.

Table I: Demographic details of the participants

\begin{tabular}{|c|c|c|c|c|}
\hline & & Major $\beta$ thalassemia & Minor $\beta$ thalassemia & Control \\
\hline \multirow[t]{2}{*}{ Sex } & Male & $35(52 \%)$ & $23(30 \%)$ & $31(22 \%)$ \\
\hline & Female & $32(48 \%)$ & $53(70 \%)$ & $113(78 \%)$ \\
\hline \multirow{4}{*}{$\begin{array}{l}\text { Age group } \\
\text { (year) }\end{array}$} & Less than 10 & $13(19 \%)$ & $1(1 \%)$ & $1(1 \%)$ \\
\hline & $11-20$ & $39(58 \%)$ & $2(3 \%)$ & $25(17 \%)$ \\
\hline & $21-30$ & $14(21 \%)$ & $34(45 \%)$ & $90(63 \%)$ \\
\hline & More than 30 & $1(2 \%)$ & $39(51 \%)$ & $28(19 \%)$ \\
\hline
\end{tabular}


Table II: Frequency counts of different types of fingerprint pattern on all fingers of participants*

\begin{tabular}{|c|c|c|c|c|c|c|c|}
\hline & Arch & Loop & Whorl & Other & P value $e^{\S}$ & $P$ value ${ }^{¥}$ & $\mathrm{P}_{\text {value }}{ }^{\mathrm{S}}$ \\
\hline Major $\beta$ thalassemia & $18(3 \%)$ & $328(49 \%)$ & $265(40 \%)$ & $59(9 \%)$ & & & \\
\hline Minor $\beta$ thalassemia & $47(6 \%)$ & $372(49 \%)$ & $287(38 \%)$ & $54(7 \%)$ & 0.011 & $<0.001$ & $<0.001$ \\
\hline Control & $120(8 \%)$ & $856(59 \%)$ & $364(25 \%)$ & $100(10 \%)$ & & & \\
\hline
\end{tabular}

*Chi square test; ${ }^{\beta}$ Difference between major and minor $\beta$ thalassemia; ${ }^{*}$ Difference between major $\beta$ thalassemia and control group; ${ }^{\$}$ Difference between minor $\beta$ thalassemia and control group

Table III: Frequency counts of different types of fingerprint on the entire set of fingers

\begin{tabular}{|c|c|c|c|c|c|c|c|c|}
\hline & & Arch & Loop & Whorl & Other & P value ${ }^{\S}$ & P value ${ }^{*}$ & P value ${ }^{\$}$ \\
\hline \multicolumn{9}{|c|}{ Right hand fingers } \\
\hline \multirow[t]{3}{*}{ Thumb } & Major Thalassemia & $0(0 \%)$ & $26(39 \%)$ & $31(46 \%)$ & $10(15 \%)$ & 0.381 & 0.027 & 0.001 \\
\hline & Minor Thalassemia & $1(1 \%)$ & $21(28 \%)$ & $38(50 \%)$ & $16(21 \%)$ & & & \\
\hline & Control & $4(3 \%)$ & $78(54 \%)$ & $39(27 \%)$ & $23(16 \%)$ & & & \\
\hline \multirow[t]{3}{*}{ Index } & Major Thalassemia & $7(10 \%)$ & $24(36 \%)$ & $28(42 \%)$ & $8(12 \%)$ & 0.251 & 0.112 & 0.809 \\
\hline & Minor Thalassemia & $13(17 \%)$ & $28(37 \%)$ & $32(42 \%)$ & $3(4 \%)$ & & & \\
\hline & Control & $27(19 \%)$ & $59(41 \%)$ & $51(35 \%)$ & $7(5 \%)$ & & & \\
\hline \multirow[t]{3}{*}{ Middle } & Major Thalassemia & $3(4 \%)$ & $44(66 \%)$ & $15(22 \%)$ & $5(7 \%)$ & 0.342 & 0.058 & 0.296 \\
\hline & Minor Thalassemia & $4(5 \%)$ & $56(74 \%)$ & $15(20 \%)$ & $1(1 \%)$ & & & \\
\hline & Control & $12(8 \%)$ & $111(77 \%)$ & $17(12 \%)$ & $4(3 \%)$ & & & \\
\hline \multirow[t]{3}{*}{ Ring } & Major Thalassemia & $0(0 \%)$ & $22(33 \%)$ & $42(63 \%)$ & $3(4 \%)$ & $0.659^{\pi}$ & $0.005^{\pi}$ & $0.015^{\pi}$ \\
\hline & Minor Thalassemia & $2(3 \%)$ & $27(36 \%)$ & $44(58 \%)$ & $3(4 \%)$ & & & \\
\hline & Control & $3(2 \%)$ & $77(53 \%)$ & $61(42 \%)$ & $3(2 \%)$ & & & \\
\hline \multirow[t]{3}{*}{ Small } & Major Thalassemia & $0(0 \%)$ & $51(76 \%)$ & $13(19 \%)$ & $3(4 \%)$ & $0.674^{\pi}$ & $0.575^{\pi}$ & $0.275^{\pi}$ \\
\hline & Minor Thalassemia & $1(1 \%)$ & $56(74 \%)$ & $17(22 \%)$ & $2(3 \%)$ & & & \\
\hline & Control & $5(3 \%)$ & $112(78 \%)$ & $23(16 \%)$ & $4(3 \%)$ & & & \\
\hline \multicolumn{9}{|c|}{ Left hand fingers } \\
\hline \multirow[t]{3}{*}{ Thumb } & Major Thalassemia & $2(3 \%)$ & $26(39 \%)$ & $30(45 \%)$ & $9(13 \%)$ & 0.660 & 0.009 & 0.113 \\
\hline & Minor Thalassemia & $1(1 \%)$ & $35(46 \%)$ & $28(37 \%)$ & $12(16 \%)$ & & & \\
\hline & Control & $4(3 \%)$ & $75(52 \%)$ & $32(22 \%)$ & $33(23 \%)$ & & & \\
\hline \multirow[t]{3}{*}{ Index } & Major Thalassemia & $2(3 \%)$ & $28(42 \%)$ & $29(43 \%)$ & $8(12 \%)$ & 0.050 & 0.002 & 0.534 \\
\hline & Minor Thalassemia & $13(17 \%)$ & $30(39 \%)$ & $26(34 \%)$ & $7(9 \%)$ & & & \\
\hline & Control & $30(21 \%)$ & $66(46 \%)$ & $38(26 \%)$ & $10(7 \%)$ & & & \\
\hline \multirow[t]{3}{*}{ Middle } & Major Thalassemia & $4(6 \%)$ & $40(60 \%)$ & $18(27 \%)$ & $5(7 \%)$ & 0.856 & 0.109 & 0.396 \\
\hline & Minor Thalassemia & $6(8 \%)$ & $48(63 \%)$ & $16(21 \%)$ & $6(8 \%)$ & & & \\
\hline & Control & $21(15 \%)$ & $92(64 \%)$ & $23(16 \%)$ & $8(6 \%)$ & & & \\
\hline \multirow[t]{3}{*}{ Ring } & Major Thalassemia & $0(0 \%)$ & $27(40 \%)$ & $38(57 \%)$ & $2(3 \%)$ & $0.752^{\pi}$ & $0.045^{\pi}$ & $0.015^{\pi}$ \\
\hline & Minor Thalassemia & $3(4 \%)$ & $28(37 \%)$ & $44(58 \%)$ & $1(1 \%)$ & & & \\
\hline & Control & $6(4 \%)$ & $77(53 \%)$ & $59(41 \%)$ & $2(1 \%)$ & & & \\
\hline \multirow[t]{3}{*}{ Small } & Major Thalassemia & $0(0 \%)$ & $40(60 \%)$ & $21(31 \%)$ & $6(9 \%)$ & 0.005 & 0.003 & 0.005 \\
\hline & Minor Thalassemia & $3(4 \%)$ & $43(57 \%)$ & $27(36 \%)$ & $27(36 \%)$ & & & \\
\hline & Control & $8(6 \%)$ & $109(76 \%)$ & $21(15 \%)$ & $6(4 \%)$ & & & \\
\hline
\end{tabular}

$\bar{*}$ *hi square test; ${ }^{\S}$ Difference between major and minor $\beta$ thalassemia; ${ }^{*}$ Difference between major $\beta$ thalassemia and control group; ${ }^{{ }^{8}} \overline{\text { Difference between minor } \beta}$ thalassemia and control group; "In these cases, because of low frequency of arch and other pattern fingerprints, these pattern excluded for better analysis 


\section{Results}

The most frequent fingerprint patterns in all fingers of participants in descending order included: loop $(\mathrm{n}=1556,54 \%)$, whorl $(\mathrm{n}=916,33 \%)$, arch $(\mathrm{n}=185$, $6 \%$ and others $(n=213,7 \%)$. A significant difference was found on fingerprint types among major thalassemic patients, minor thalassemic patients and the control group and similarly between minor thalassemic patients and control group.

Table II shows the frequency counts of different types of fingerprint pattern on all fingers of participants. The means for frequency of loop fingerprints on all fingers in major thalassemic patients, minor thalassemic patients, and normal individuals were $4.9,4.9$ and 5.9 respectively, which was significantly higher in normal individuals than thalassemic patients (ANOVA test, $\mathrm{p}=0.005$ ). Furthermore, the mean for the frequency of whorl fingerprint pattern on all fingers in major thalassemic patients, minor thalassemic patients, and normal individuals were $3.9,3.8$ and 2.5 respectively, which was significantly lower in normal individuals compared to thalassemic patients (ANOVA test, $\mathrm{p}=0.001$ ).

Table III shows the frequency counts of different types of fingerprint on the entire set of fingers. As the statistics in the table show, there is not a significant difference on the fingerprint types between the two groups of thalassemic patients while there is a significant difference between thalassemic and control groups on the fingerprints of the right-hand thumb, right-hand ring finger, left-hand ring finger and left-hand little finger. Furthermore, major thalassemic and control groups differed significantly on the fingerprint types on the right-hand middle finger, left-hand thumb, and lefthand index finger. Overall, the frequency count of whorl fingerprint pattern was higher in thalassemic patients than control group participants, while the frequency count of loop fingerprint pattern in thalassemic patients was lower than that of the control group. No significant difference was observed between female and male thalassemic patients on fingerprint types $(\mathrm{p}>0.05)$.

\section{Discussion}

The present findings show that, loop fingerprint pattern, like control group, is the most common type of fingerprint in thalassemic patients. However, whorl type fingerprint is more frequent in thalassemic patients compared with normal individuals and the loop type fingerprints in thalassemic patients counted less than normal individuals. Furthermore, arch type fingerprint occurs less frequently in major thalassemic patients than minor thalassemic ones.

The number of studies focusing on examining fingerprints in thalassemic patients is limited and with mixed results ${ }^{22-28}$. Russian researchers, for instance, found that whorl type fingerprint occurs more frequently than other patterns in thalassemic patients ${ }^{23}$ while a study conducted in Italy indicated the higher frequency of loop type fingerprint and lower frequency of whorl fingerprints ${ }^{25}$. Moreover, unlike our findings, which showed that whorl fingerprints on all fingers in general and on certain fingers of thalassemic patients in particular outnumbered those of control group, Dogramaci et al. found that although the frequency of different patterns of fingerprints may differ between the control group and major and minor thalassemic patients this difference is not significant ${ }^{29}$. Saha et al shows that only the abnormal loop pattern of the fingerprint on the fifth finger of women's left hand was significantly different from those of male patients, their minor thalassemic parents and the control group ${ }^{27}$. These could be the use of different fingerprinting methods and interpretations. The present study was conducted using advanced Henry method while Dogramaci made use of Cummins and Midlo's method ${ }^{29}$. Some research findings have shown that fingerprint patterns of patients may vary across geographical areas ${ }^{30}$.

Human's fingerprints are formed in the fetal period and remain unchanged during their life. Examining fingerprints is a simple and accessible means in the study of genetic diseases in general and detection of abnormal chromosomes in particular ${ }^{26}$. Abnormality of patients' fingerprints has been examined in diseases such as Down's syndrome, psychiatric diseases, glaucoma, multiple sclerosis, Alzehimer's disease, uterus cancer, Wilson's disease, psoriasis, vitiligo, brachial plexus palsy, congenital cardiac diseases, borderline personality disorders, schizophrenia, and autism ${ }^{12-22}$. Although morphological and clinical studies have shown that environmental and genetic factors affect dermatoglyphic patterns ${ }^{31-33}$, this simple method could supplement existing ones in the early diagnosis of thalassemia.

This is the first study examining the fingerprint patterns of thalassemic patients in Iran. Fingerprint examination is a non-invasive, simple, inexpensive and efficient method to supplement existing thalassemia screening methods. However, the limitation lying in this method is that fails to take into account skin folds between the fingers and the line patterns on the sole. Furthermore, participant 
patients came form only one healthcare center while geographical area may affect fingerprint types and patterns in patients ${ }^{30}$. Therefore, further research is highly recommended with a larger sample size and across various geographical areas.

\section{References}

1. Kutlar F. Diagnostic approach to hemoglobinopathies. Hemoglobin 2007; 31: 243-50.

2. Haghshenas M, Zamani J. [Thalassemia]. 1st ed. Shiraz, Shiraz University of Medical Sciences Publishing Center, 1997. [Book in Persian]

3. Najmabadi H, Karimi-Nejad R, Sahebjam S, Pourfarzad F, Teimourian S, Sahebjam F. The betathalassemia mutation spectrum in the Iranian population. Hemoglobin 2001; 25: 285-96.

4. Fucharoen S, Winichagon P. Thalassemia and abnormal hemoglobin. Int J Hematol. 2002; 76 Suppl: 83-89.

5. Shine I, Lai S. Strategy to detect beta-thalassemia minor. Lancet 1977; i: 692-94.

6. Srivastava PC, Bevington JM. Iron deficiency and/or Thalassaemia trait. Lancet 1973; i (7807): 832.

7. Mentzer Jr WC. Differentiation of iron deficiency from Thalassaemia Trait. Lancet 1973; i (7808): 882.

8. Lee K. Routine erythrocyte measurements in diagnosis of iron deficiency anemia and thalassemia major. Am J Clin Pathol. 1996; 66: 870 -77.

9. Weatherall DJ. Thalassemia. In: Williams WJ, et al. Hematology. 4th ed. New York, McGraw Hill Publishing Co, 1990, pp 510-39.

10. Alfadhli SM, Al-Awadhi AM, Alkhaldi D. Validity assessment of nine discriminant functions used for the differentiation between iron deficiency anemia and Thalassemia minor. J Trop Pediatr. 2007; 53: 93-97.

11. Polani PE, Polani N. Chromosome anomalies, mosaicism and dermatoglyphic asymmetry. Ann Hum Genet. 1969; 32: 391.

12. Novak-Laus K, Milicić J, Tedeschi-Reiner E, Iveković R, Korsić J, Zrinsćak O, Mandić Z. Analysis of the qualitative dermatoglyphics of the digito-palmar complex in patients with primary open angle glaucoma. Coll Antropol. 2006; 30: 163-70.

13. Supe S, Milicić J, Pavićević R. Analysis of the quantitative dermatoglyphics of the digito-palmar complex in patients with multiple sclerosis. Coll Antropol. 1997; 21: 319-25.

14. Weinreb HJ. Dermatoglyphic patterns in Alzheimer's disease. J Neurogenet. 1986; 3: 233-46.

15. Bejerano $\mathrm{M}$, Yakovenko $\mathrm{K}$, Katznelson $\mathrm{MB}$, Kobyliansky E. Relationship between genetic anomalies of different levels and deviations in dermatoglyphic traits. Part 7: Dermatoglyphic peculiarities of females with cervical and endometrial carcinoma. Z Morphol Anthropol. 2001; 83: 75-108.
16. David TJ, Ajdukiewicz AB. Palmar dermatoglyphs in Wilson's disease. Br Med J. 1972; 3(5830): 825-26.

17. Pour-Jafari H, Farhud DD, Yazdani A, Hashemzadeh Chaleshtori M. Dermatoglyphics in patients with eczema, psoriasis and alopecia areata. Skin Res Technol. 2003; 9: 240-44.

18. Iqbal S, Premalatha S, Zahra A. Dermatoglyphics in vitiligo. Int J Dermatol. 1985; 24: 510-13.

19. Polovina S, Cvjeticanin M, Milicić J, Proloscić TP. Dermatoglyphs and brachial plexus palsy. Coll Antropol. 2006; 30: 559-63.

20. Hale AR, Philips JH, Burch GE. Features of palmar dermatoglyphics in congenital heart disease: A report on the variants frequently associated with congenital lesions of the heart. JAMA. 1961; 176: 41-45.

21. Jelovac N, Milicić J, Milas M, Dodig G, Turek S, Ugrenović Z. Dermatoglyphic analysis in borderline personality disorder and schizophrenia: Results of a Croatian study. Coll Antropol. 1998; 22: 141-48.

22. Milicić J, Bujas Petković Z, Bozikov J. Dermatoglyphs of digito-palmar complex in autistic disorder: family analysis. Croat Med J. 2003; 44: 469-76.

23. Mutalimova AB, Kurdiumova TIu. Dermatoglyphics in beta-thalassemia major. Genetika. 1975; 11: 150-51.

24. Gualdi-Russo E, Martuzzi-Veronesi F, Zannotti M. Digital dermatoglyphics in children with betathalassemic trait. Hum Hered. 1981; 31; 238.

25. Dallapiccola D, Capra L, Baricordi O, Mazilli C. Dermatoglyphic studies in patients with Cooley's anemia and Cooley's trait. Acta Genet Med Gemellol. (Roma.) 1975: 24: 283-93.

26. Gualdi Russo E. Biological distances in dermatoglyphics of beta-thalassemic subjects. Acta Anthropogenet. 1984; 8: 223-30.

27. Saha KC, Chatterjea JB, Mukherjee DP. Dermatoglyphics in thalassaemia syndrome. J Indian Med Assoc. 1973; 61: 205-11.

28. Stomeo C, Tannoia N. Hand dermatoglyphics in a group of patients with thalassemia from Puglia. Minerva Pediatr. 1979; 31: 1085-90.

29. Dogramaci AC, Savas N, Bagriacik MA. Dermatoglyphs in patients with beta-thalassemia major and their thalassemia carrier parents. Coll Antropol. 2009; 33: 607-11.

30. Gasiorowski A. Regional differentiation of palm dermatoglyphs in rural population in Poland. Ann Agric Environ Med. 2005; 12: 277-80.

31. Penrose LS: Finger-prints, palms and chromosomes. Nature 1963; 197: 933-35.

32. Penrose LS: Fingerprint patterns and the sex chromosomes. Lancet 1967; i: 298-99.

33. Penrose LS, Loesch D. The effect of sex chromosomes characteristics of dermal ridges on palms and fingerprints. Genet Pol. 1969; 10: 328-32. 
